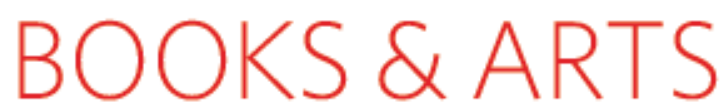

\title{
Before the storm
}

\section{Katrina grabbed the headlines recently, but hurricanes have been a focus of attention for centuries.}

\author{
Divine Wind: The History and Science of \\ Hurricanes \\ by Kerry Emanuel \\ Oxford University Press: 2005.304 pp. \\ $\$ 45, £ 26.99$
}

\section{Howard B. Bluestein}

The tropical atmosphere has recently been surpassing itself. In late August, Hurricane Katrina, following an encounter with South Florida, devastated parts of the US Gulf coast and led to the inundation of New Orleans. This hurricane has been called the worst natural disaster ever to hit the United States. The total number of fatalities has not yet been tallied, but it is expected to be high, and the number of people displaced, damage to property, and economic loss from the disappearance of businesses and interruption of oil and gas production are staggering. Hurricane Ophelia, which came soon after Katrina, brushed the Carolina coasts, and Hurricane Rita struck Louisiana and Texas. During the previous hurricane season, Florida was struck by a record number of hurricanes.

Divine Wind by Kerry Emanuel is therefore timely. Whereas other books on hurricanes focus on history, such as Erik Larson's Isaac's Storm (Little Brown, 1999), or on science, like Rick Anthes' Tropical Cyclones (American Meteorological Society, 1982), Divine Wind addresses both. Emanuel deftly interweaves an exposition of the science of hurricanes with historical accounts of major tropical cyclones and artists' impressions of the feelings that these tropical tempests instil. He also describes the challenge of predicting and understanding hurricanes. The book does a remarkable job of covering the history, science and terrible beauty of hurricanes, which makes it tempting not only to the storm aficionado and professional scientist, but also to the general public.

Emanuel's inclusion of art has a welcome humanizing effect. A scientific discussion of what happens when a hurricane makes landfall is framed within Richard Strauss's tone poem Death and Transfiguration. Technical figures such as satellite and radar images are intermixed with historical photographs and realistic, abstract and sometimes apocalyptic paintings. There are poems of the regular, not tone, variety, and colourful and easy-tointerpret figures illustrating scientific principles. Instrumentation such as radar, satellites,

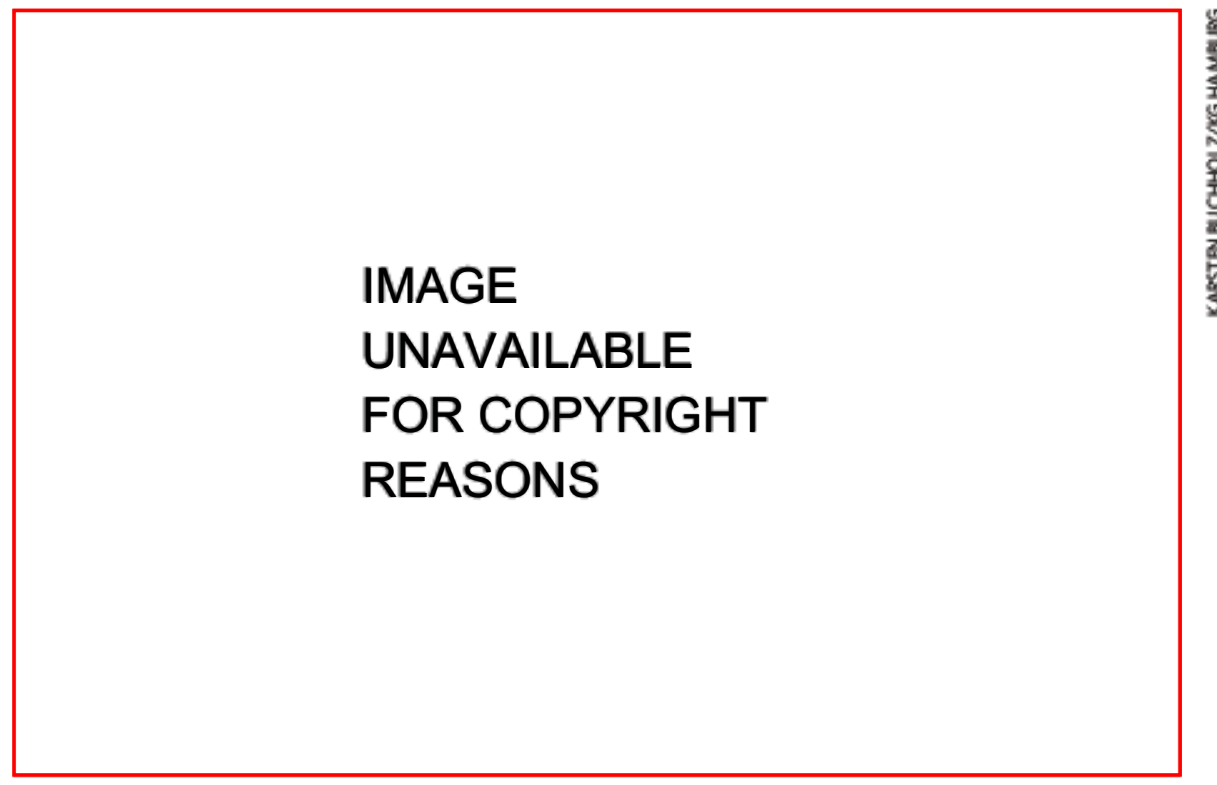

Tossed and blown: ships take a battering in Engel Hoogerheyden's 1795 painting The Eye of the Hurricane.

aircraft, remotely piloted aircraft and scatterometers is also described and explained. Throughout, Emanuel achieves a perfect balance between the scientific and non-scientific aspects of hurricanes.

My favourite chapter is a photo essay depicting the inside of a hurricane or typhoon. Hurricanes are dangerous, but they are beautiful too, if observed from the safety of an aircraft inside the eye of the storm or from space. One photograph, taken during a US Air Force reconnaissance flight, shows the eye of a typhoon viewed from below. Others have views looking straight down at the turbulent ocean surface and windblown spray, and there is even one image from the space shuttle. Emanuel compares a view of the eye of a typhoon with a scene from Dante's Inferno.

There are accounts of major historical hurricanes and typhoons. Some of them affected the course of history, such as the typhoons that struck Japan in the thirteenth century (the 'divine wind', or kamikaze, that saved Japan from Kublai Khan), and a hurricane in the sixteenth century that interfered with an attempt by the French to settle Florida. The 'great hurricane' of 1780 in the Caribbean was one of the deadliest hurricanes ever to strike in that part of the world. The book also covers the 1900 Galveston hurricane, the New England hurricane of 1938, Hurricane Camille in 1969, Cyclone Tracy in Australia in Christmas 1974 and Hurricane Andrew in 1992. The effects of Katrina are likely to be as long lasting, politically, socially and economically, as those of its predecessors. Other books have dealt with the historical accounts in more depth, but the overall effect of those in Divine Wind is unique.

Emanuel notes a similarity between The Tempest and an account of a hurricane in 1609 given by William Strachey, an acquaintance of William Shakespeare. Many scholars say this rules out Edward De Vere as a possible author of The Tempest, because he died before Strachey told his tale. Strachey's account itself is poetic:

For four and twenty hours the storm in a restless tumult, had blown so exceedingly, as we could not apprehend in our imagination any possibility of greater violence, yet did we still find it, not more terrible, but more constant, fury added to fury, and one storm urging a second more outrageous than the former...The Sea swelled above the clouds, and gave battle unto heaven.

A pioneering hurricane researcher, Emanuel presents the science at a level that is not too technical for non-specialists, yet is sufficient 
to describe the basic physics with few equations. Hurricane formation, energetics and ocean interaction are all clearly explained. The fundamentals of numerical weather prediction using computers, including chaos theory and its relevance to forecasting, are also well treated. The only minor criticism I have is that each of the forces that control the behaviour of hurricanes is treated separately. It would have been nice if the effects of all the forces had been summarized, particularly in the section on numerical weather prediction, where only the sum of all the forces is noted.

Emanuel has recently been in the public eye as a result of his recent letter in Nature $(436,686-688,2005)$, in which he suggested that any further warming of the troposphere might increase the destructive potential of tropical cyclones. His book ends with some further provocative thoughts on hurricanes and dimate.

Howard B. Bluestein is at the School of Meteorology, University of Ollahoma, Norman, Oklahoma 73019, USA.

\section{Fetal affliction}

\author{
The Fetal Matrix: Evolution, Development \\ and Disease \\ by Peter Gluckman \& Mark Hanson \\ Cambridge University Press: 2005. 272 pp. \\ $€ 50, \$ 90$ (hbk); $€ 24.99, \$ 39.99$ (pbk)
}

\section{Michael Sargent}

The idea of the womb as a tranquil nursery, untroubled by worldly pressures, is charming but wrong: the unborn baby reacts and adapts to its unique environment, with profound consequences for later life. This is the view that emerged in the 1990s from some remarkable investigations led by David Barker at the University of Southampton. Retrospective studies of cohorts of people born in the 1920 s indicated that babies that were small for their gestational age were more susceptible than average in middle age to coronary heart disease, type 2 diabetes, hypertension and osteoporosis.

The Fetal Matrix by Peter Gluckman and Mark Hanson is a fascinating and important book about the responses of the mammalian fetus to its environment. Building on Barker's proposals, the authors suggest that the fetus can respond to a potentially harsh nutritional landscape by scaling down the developmental enterprise to create a 'survival phenotype' - a small, lean body with undiminished capacity for reproduction. Visceral organs are underdeveloped relative to the brain because fewer cells are allocated to capillaries in muscle, to nephrons, to the liver or to insulin secretion. Energy is conserved by avoiding unnecessary musde growth and using any excess to create fat deposits that can be mobilized when food is scarce. For most of human history, the survival phenotype has been an important and appropriate adaptation when food and population were in a delicate malthusian balance.

About sixty years ago, when food became available in unprecedented abundance in the developed world and work became less physically demanding, the survival phenotype began to be a liability for some people. Those affected were likely to develop abdominal fat, high blood pressure and reduced responsiveness to a glucose surge (insulin resistance)

\section{IMAGE UNAVAILABLE FOR COPYRIGHT REASONS}

Womb for improvement? Events before birth can have huge consequences for health in later life.

- all signs of the 'metabolic syndrome'

Barker's view of the fetal origins of disease is not universally accepted. Unfortunately, readers of this book who want to disentangle the arguments for themselves will be frustrated by the unsatisfactory link between the text and specific references. But compelling support for the concept, less dependent on fine statistical judgements, comes from work using experimental animals. This shows that the survival phenotype and its pathological consequences, hypertension and insulin resistance, can be induced in utero when the mother's diet is deficient in protein or micronutrients, or by treatment with the stress hormone cortisol.

The survival phenotype can be provoked in the fetus by undernutrition, by the physical constraint imposed by having a small mother, or by cortisol crossing the placenta causing growth restriction and accelerated maturation. A constraint on birth weight is inevitable in small mothers and is repeated again when their daughters (also small) become pregnant. This epigenetic phenomenon is seen with special poignancy in some parts of India, where persistent malnutrition generates a population of phenotypically small mothers whose babies are among the smallest known. The long-term effect on unborn babies of a period of malnutrition of precise intensity and duration is best known from the Dutch Hongerwinter of 1944-45. Many babies conceived during this episode developed the survival phenotype but were often only marginally underweight.

What provokes the survival phenotype? Maternal nutritional deficiency or exposure to cortisol causes the promoters of certain genes to remain unmethylated in the early embryo, precipitating changes of gene expression that confer an altered phenotype that persists into adult life. These genes affect activities as diverse as apoptotic remodelling of the embryo and the capacity to groom offspring, and it is a fair bet that more important examples will emerge. Offspring with the survival phenotype that gain weight quickly during childhood are prone, as adults, to the characteristic pathology of the metabolic syndrome. In countries that are now undergoing rapid economic development, a serious issue of public health is unfolding that is likely to affect people whose standard of living is increasing. Indeed, the World Health Organization has predicted that in 20 years' time, $5 \%$ of the world's population will develop type 2 diabetes.

This book is a thought-provoking account of a topic in which developmental biology, physiology and clinical medicine intersect. It focuses on the idea that the development of the mammalian fetus normally anticipates the postnatal environment, triggering a "predictive adaptive response", but may misjudge the situation. A fetus with the survival phenotype that enters an unexpectedly bounteous world starts on a developmental trajectory that may predispose the individual to ill health.

The authors convey admirably the physiological implications of an important idea, but they are less forthcoming about other dimensions of the subject that might appeal to a nonspecialist reader. For example, the literature suggests that the status of the immune system and the inflammatory response, and possibly certain behavioural and psychological characteristics, are affected by events in the uterus. Similarly, investigations by historians into trends in human physique are not included. These are immensely interesting records that are an important barometer of life experience resulting from physiological decisions taken in utero.

I was glad to learn that 'fetus' - Latin for 'offspring, and used in English since the fourteenth century - is the correct usage and that 'foetus' is a recent pseudo-Greek affectation. More obscurely, the 'matrix' of the title alludes to a surprising dictionary definition (it means 'womb') and perhaps to the set of variables that can have such far-reaching consequences for the fetus.

Michael Sargent is a developmental biologist at the National Institute for Medical Research, Mill Hill, London and the author of Biomedicine and the Human Condition: Challenges, Risks and Rewards. 